\title{
Pengaruh Perceived Value dan Perceived Risk terhadap Willingness to Use Studi Kasus Carpooling Mobile Application di Indonesia
}

\author{
Adista Ari Ramadanti dan Janti Gunawan \\ Departemen Manajemen Bisnis, Institut Teknologi Sepuluh Nopember (ITS) \\ e-mail: adista16@mhs.mb.its.ac.id
}

\begin{abstract}
Abstrak-Peningkatan jumlah kendaraan mobil yang terus terjadi menyebabkan kemacetan dan polusi udara mendorong pemerintah membuat kebijakan pengurangan penggunaan kendaraan mobil. Selain itu transportasi juga menjadi kendala pada sektor pariwisata di Indonesia. Hal tersebut dapat menjadi peluang bagi perusahaan carpooling mobile application. Namun, kenyataannya saat ini pengunduh carpooling mobile application masih terbilang sedikit, sehingga tantangan bagi perusahaan adalah meningkatkan popularitas dan willingness to use pengguna. Penelitian ini bertujuan untuk mengetahui pengaruh perceived value dan perceived risk terhadap willingness to use carpooling mobile application. Pengolahan data analisis PLS-SEM. Pengumpulan data dilakukan menggunakan kuesioner online dan didapatkan 64 sampel yang memiliki kriteria pernah menggunakan carpooling mobile application dalam satu tahun terakhir. Penelitian ini menghasilkan temuan bahwa perceived value berpengaruh positif terhadap willingness to use. Sementara perceived risk berpengaruh negatif terhadap willingness to use.
\end{abstract}

Kata Kunci-Carpooling Mobile Application, Perceived Risk, Perceived Value, Willingness to Use.

\section{PENDAHULUAN}

$\mathrm{T}$ RANSPORTASI merupakan kebutuhan utama bagi masyarakat untuk dapat menyelesaikan aktivitas bepergian yang dilakukan sehari-hari. Mobil sebagai salah satu moda transportasi massal berupa kendaraan penumpang terus meningkat jumlahnya setiap tahun di Indonesia. Pada tahun 2013 jumlah kendaraan mobil penumpang mencapai 11.484.514 unit yang terus meningkat hingga tahun 2017 jumlahnya mencapai 15.493 .068 unit [1]. Padatnya jalan raya dengan penggunaan mobil melibatkan konsumsi bahan bakar yang berlebihan, polusi udara dan kebisingan, kemacetan, dan penggunaan lahan yang berlebih [2].

Pemerintah, sebagai pemangku kepentingan utama penyedia infrastruktur, terus berupaya membuat kebijakan terkait pengurangan jumlah penggunaan kendaraan. Sebagai contoh, pemerintah DKI Jakarta menerapkan kebijakan kawasan 3-in-1 mulai tahun 2003, dan terus mencari cara mengurangi beban kendaraan di jalan raya, seperti dengan menerapkan kebijakan plat nomor ganjil genap mulai tahun 2016 [3]. Pemerintah daerah lain, Kota Bandung, berencana membuat kebijakan program carpooling untuk berangkat ke kantor yang dilakukan Dishub Kota Bandung dan sedang dalam tahap uji coba pada tanggal 11 Maret 2019 [4].
Di sisi lain, Indonesia dengan potensi pariwisatanya ternyata memiliki kendala utama dalam pengembangan pariwisatanya yaitu masih banyak transportasi yang belum menunjang pariwisata [5]. Saat ini transportasi umum yang nyaman dan dapat menjangkau tempat wisata masih terbatas. Hal ini menyebabkan wisatawan lebih memilih kendaraan pribadi atau sewa kendaraan sebagai moda transportasinya. Berdasarkan riset moda transportasi yang paling banyak digunakan pada tahun 2018 adalah mobil pribadi dan sewa kendaraan dengan persentase sebesar 67,14 persen [6]. Jika kondisi ini dibiarkan, maka daerah-daerah yang belum tersedia transportasi umum akan terus terbatas pengembangan pariwisatanya. Selain itu daerah yang hanya bisa dijangkau dengan kendaraan pribadi menjadi berkurang kenyamanannya karena macet, seperti yang terjadi di jalur Puncak pada saat hari libur

Selain itu, biaya transportasi merupakan pertimbangan dalam berwisata. Biaya transportasi merupakan pengeluaran terbesar dalam melakukan perjalanan wisata, dengan persentase sebesar 34,0 persen pada 2018 [6]. Carpooling dapat menjadi salah satu solusi untuk mengurangi pengeluaran untuk biaya transportasi dan menjadi pilihan transportasi yang nyaman untuk berwisata.

Berdasarkan permasalahan yang ada Carpooling mungkin dapat menjadi salah satu alternatif transportasi yang nyaman dan terjangkau. Hal tersebut juga dapat menjadi peluang bagi perusahaan penyedia layanan carpooling Saat ini sudah banyak ditawarkan berbagi kendaraan, dan dengan mudah melalui layanan online, yang difasilitasi oleh mobile application seperti, Nebengers, Bistar, Sejalan, dan lain-lain.

Namun, penggunaan carpooling mobile application cenderung masih sedikit dan kurang populer di Indonesia. Hal tersebut menjadi tantangan dan perhatian bagi perusahaan penyedia jasa carpooling untuk dapat menawarkan produk dan layanan yang sesuai dengan keinginan dan kebutuhan pelanggan. Perusahaan carpooling perlu mengetahui bagaimana meningkatkan popularitas mereka dan meningkatkan willingness to use carpooling mobile application.

Willingness to use konsumen dapat menjadi acuan perusahaan untuk mengetahui karakter pengguna potensial. Untuk meningkatkan willingness to use carpooling mobile application dibutuhkan pemasaran produk yang tepat. Sehingga diperlukan investigasi mengenai faktor-faktor yang mempengaruhi willingness to use carpooling mobile 
application. Menurut penelitian Wang et al. [7] willingness to use dipengaruhi oleh perceived value dan perceived risk.

Berdasarkan penjabaran di atas penelitian ini bertujuan untuk menganalisis pengaruh perceived value dan perceived risk terhadap willingness to use carpooling mobile application. Sehingga, penelitian ini dapat memberikan kontribusi manajerial kepada carpooling mobile application untuk mengetahui faktor-faktor dari perspektif value dan risk yang mempengaruhi willingness konsumen menggunakan carpooling mobile application. Dengan mengetahui faktorfaktor yang mempengaruhi willingness penggunaan carpooling mobile application, perusahaan dapat mengetahui cara untuk memasarkan layanan tersebut dengan tepat.

\section{TINJAUAN PUSTAKA}

\section{A. Carpooling Mobile Application}

Carpooling adalah berbagi tumpangan sehingga dua orang atau lebih bepergian bersama dalam satu kendaraan [8]. Manfaat carpooling, yaitu meningkatkan aliran lalu lintas, menghemat waktu, dan menurunkan konsumsi bahan bakar [9]. Tujuan utama carpooling mobile application adalah untuk menciptakan komunitas online, yang anggotanya dapat bertindak sebagai pengemudi yang menawarkan perjalanan atau penumpang yang mencari kendaraan dari satu tempat ke tempat lain [10].

\section{B. Willingness to Use}

Willingness to use pada penelitian Wang et al. [7] menggambarkan niat penggunaan konsumen. Willingness to use pada penelitian Wang [11] menggambarkan keinginan menggunakan, sementara Hohenberger et al. [12] menggambarkan willingness to use sebagai rencana penggunaan dalam penelitian mengenai adopsi dan penerimaan teknologi.

\section{Perceived Value}

Perceived value merupakan penilaian keseluruhan konsumen atas manfaat produk berdasarkan persepsi tentang apa yang diterima dan apa yang diberikan [13]. Untuk produk atau layanan tertentu percaived value dapat meningkat ketika pengguna percaya bahwa manfaatnya lebih besar daripada biayanya [14].

Perceived value dapat dilihat dari dimensi nilai funsional (utilitarian value), nilai emosional (hedonic value), dan nilai sosial (social value) [7]. Utilitarian value berasal dari manfaat yang terkait dengan tugas, fungsional atau objektif dari pengalaman konsumsi.[15]. Hedonic value berasal dari aspek multi-indera dan emosional dari pengalaman berbelanja [15]. Social value merupakan penilaian keseluruhan konsumen atas manfaat dan pengorbanan yang melibatkan interaksi dengan orang lain [7].

\section{Perceived Risk}

Perceived risk berfokus pada kekhawatiran konsumen tentang pelanggaran pihak penjual atas kewajiban formal dan informal, misalnya dengan melanggar norma kerahasiaan, atau melanggar kualitas produk atau layanan [16]. Konsep perceived risk yang paling sering digunakan peneliti konsumen mendefinisikan risk sebagai persepsi konsumen tentang ketidakspastian dan konsekuensi buruk dari pembelian suatu produk atau layanan [17].

Perceived risk dapat dilihat dari dimensi risiko privasi (privacy risk), risiko kinerja (performance risk), risiko keamanan (security risk), dan risiko konflik (conflict risk) [7]. Privacy risk adalah potensi kehilangan kendali atas informasi pribadi, seperti ketika data pribadi digunakan tanpa sepengetahuan atau seizin pengguna [18]. Performance risk serupa dengan risiko fungsional yang melibatkan keyakinan konsumen bahwa produk atau layanan yang dibeli tidak akan menawarkan manfaat yang disukai konsumen [19]. Security melibatkan masalah berkendara, seperti pengemudi yang tidak dikenal dan kemampuan mereka untuk melacak lokasi [20]. Conflict risk adalah risiko terkait kurangnya mekanisme kompensasi kecelakaan yang komprehensif dan keamanan yang memadai untuk kehilangan waktu, kerusakan finansial, atau cedera pribadi, yang menjadi perhatian konsumen dalam praktiknya [21] [7].

\section{METODOLOGI}

\section{A. Desain Penelitian}

Jenis penelitian yang digunakan adalah conclusive design yang bertujuan menguji hipotesis tertentu dan menguji hubungan. Pada penelitian ini menggunakan multiple-cross sectional karena responden penelitian terdiri dari beberapa sampel. Data yang dibutuhkan adalah data primer dari responden yang menggunakan aplikasi carpooling mobile application.

\section{B. Sampel Penelitian}

Kriteria dari sampel penelitian adalah wanita dan pria yang pernah menggunakan carpooling mobile application dalam satu tahun terakhir. Jumlah minimal sampel pada penelitian ini adalah 40 responden. Pengumpulan data dilakukan menggunakan kuesioner online dan menggunakan teknik sampling snowball.

\section{Metode Analisis Data}

Analisis data dilakukan menggunakan Partial Least Square - Structural Equation Model (PLS-SEM). Analisis tersebut digunakan untuk menguji hipotesis pada penelitian ini. Analisis PLS-SEM terdiri dari 2 tahap, yaitu uji model pengukuran (outer model) dan uji model struktural (inner model).

\section{Model dan Hipotesis Penelitian}

Model penelitian ini mengacu pada penelitian sebelumnya yang telah dilakukan Wang et al. [7], dapat dilihat pada Gambar 1.

Hipotesis penelitian yang akan diuji menggunakan PLS-SEM adalah sebagai berikut.

$\mathrm{H} 1:$ Perceived value berpengaruh positif terhadap willingness to use carpooling mobile application

H2a: Utilitarian value merupakan komponen formative first order dari perceived value 
Tabel 1 .

Uji Convergent Validity

\begin{tabular}{clcc}
\hline \hline Konstruk & Indikator & Outer Loading & AVE \\
\hline \multirow{4}{*}{ Utilitarian Value } & UV1 & 0,773 & \\
& UV2 & 0,872 & 0,627 \\
& UV3 & 0,723 & \\
Hedonic Value & HV1 & 0,839 & \\
& HV2 & 0,847 & 0,737 \\
& HV3 & 0,888 & \\
\hline \hline
\end{tabular}

Tabel 1.

Uji Convergent Validity (Lanjutan)

\begin{tabular}{|c|c|c|c|}
\hline Konstruk & Indikator & Outer Loading & $A V E$ \\
\hline \multirow{3}{*}{ Social Value } & SV1 & 0,874 & \multirow{3}{*}{0,777} \\
\hline & SV2 & 0,913 & \\
\hline & SV3 & 0,856 & \\
\hline \multirow{4}{*}{ Privacy Risk } & PRIR1 & 0,869 & \multirow{4}{*}{0,809} \\
\hline & PRIR2 & 0,943 & \\
\hline & PRIR3 & 0,860 & \\
\hline & PRIR4 & 0,923 & \\
\hline \multirow{3}{*}{ Performance Risk } & PERR1 & 0,831 & \multirow{3}{*}{0,592} \\
\hline & PERR2 & 0,593 & \\
\hline & PERR3 & 0,856 & \\
\hline \multirow{3}{*}{ Security Risk } & SR1 & 0,695 & \multirow{3}{*}{0,627} \\
\hline & SR2 & 0,844 & \\
\hline & SR3 & 0,828 & \\
\hline \multirow{2}{*}{ Conflict Risk } & CR1 & 0,941 & \multirow{3}{*}{0,895} \\
\hline & CR2 & 0,951 & \\
\hline \multirow{4}{*}{ Willingness to Use } & WTU1 & 0,863 & \\
\hline & WTU2 & 0,799 & \multirow{3}{*}{0,673} \\
\hline & WTU3 & 0,867 & \\
\hline & WTU4 & 0,746 & \\
\hline
\end{tabular}

$\mathrm{H} 2 \mathrm{~b}$ : Hedonic value merupakan komponen formative first order dari perceived value

H2c: Social value merupakan komponen formative firstorder dari perceived value

$\mathrm{H} 3$ : Perceived risk berpengaruh negatif terhadap willingness to use carpooling mobile application

H4a: Privacy risk merupakan komponen formative first order dari perceived risk

H4b: Performance risk merupakan komponen formative first order dari perceived risk

$\mathrm{H} 4 \mathrm{c}$ : Security risk merupakan komponen formative first order dari perceived risk

$\mathrm{H} 4 \mathrm{~d}$ : Conflict risk merupakan komponen formative first order dari perceived risk

H5: Perceived risk berpengaruh positif pada moderasi hubungan antara perceived value dan willingness to use carpooling mobile application

\section{ANALISIS DAN DISKUSI}

Jumlah sampel yang lolos dan dapat digunakan pada analisis PLS-SEM sebanyak 64 responden. Analisis PLS SEM digunakan untuk menguji hipotesis penelitian. Pada penelitian ini software yang digunakan adalah SmartPLS. Evaluasi model dilakukan pada model pengukuran (outer model) dan model struktural (inner model).

\section{A. Model Pengukuran (Outer Model)}

Evaluasi model pengukuran dilakukan untuk menilai validitas dan reliabilitas model. Untuk mengevaluasi model pengukuran pada first order yang bersifat reflektif dapat dilihat dari convergent validity, discriminant validity, dan internal

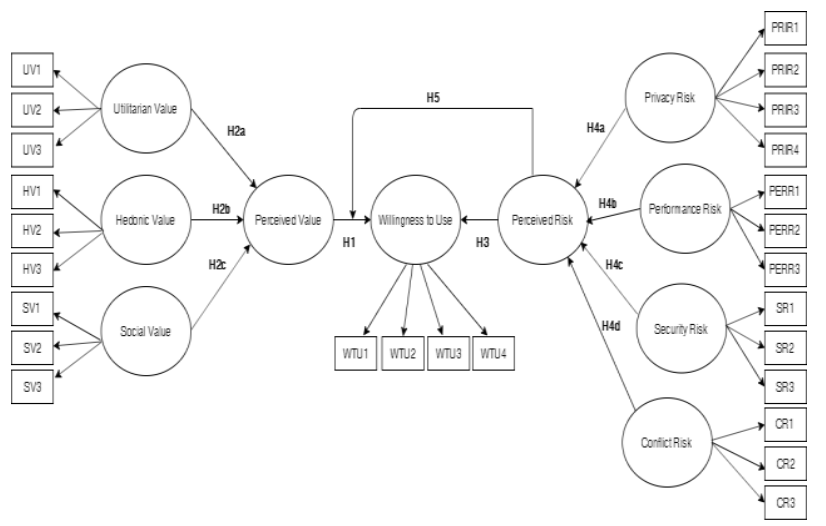

Gambar 1. Model Penelitian.

consistency reliability. Sementara untuk mengevaluasi second order yang bersifat formatif dapat dilihat dari weight dan juga nilai Variance Inflation Factor.

Pada uji convergent validity nilai loading masih bisa diterima dengan nilai minimal 0,5 dan nilai AVE sebesar 0,5 atau lebih menunjukkan validitas konvergen yang memuaskan [22]. Nilai AVE pada setiap konstruk telah memenuhi batas minimal yaitu lebih dari 0.5. Sementara nilai outer loading terdapat nilai yang dibawah 0,5. Indikator CR3 memiliki nilai 0,428 sehingga perlu dilakukan reduksi dengan menghapus indikator tersebut. Setelah reduksi, seluruh skor menunjukkan angka yang valid, baik nilai outer maupun nilai AVE diatas 0,5. Hal ini menunjukkan bahwa setiap indikator telah menunjukkan korelasi terhadap konstruknya. Berikut hasil uji convergent validity setelah dilakukan reduksi terlihat pada Tabel 1 .

Uji discriminant validity menunjukkan bahwa indikator setiap sub variabel dan variabel memiliki skor yang lebih tinggi apabila dipasangkan dengan sub variabel dan variabelnya masing-masing. Hal tersebut menunjukkan indikator pertanyaan mencerminkan sub variabel dan variabelnya masing-masing dan tidak ada hubungan yang lebih besar dengan sub variabel dan variabel yang lain. Sehingga, dapat dikatakan setiap indikator valid.

Pada uji internal consistency reliability suatu data dapat dikatakan reliabel apabila nilai Cronbach's Alpha lebih besar atau sama dengan 0,6 dan nilai Composite Reliability (CR) lebih besar atau sama dengan 0,7 [22]. Pada Tabel 2 dapat dilihat nilai Cronbach's Alpha lebih besar dari 0,6 dan nilai Composite Reliability lebih besar 0,7. Hal tersebut menandakan bahwa setiap indikator dapat dikatakan relibel untuk mengukur setiap konstruk.

Dalam hal langkah-langkah formatif, diperlukan untuk memeriksa bobot (weight) faktor yang mewakili analisis korelasi dan memberikan informasi tentang bagaimana sub variabel berkontribusi terhadap variabelnya masing-masing. Nilai bobot harus lebih besar dari 0.1 [23]. Berdasarkan hasil uji pada Tabel 3 nilai bobot seluruh sub variabel lebih besar dari 0.1 yang menunjukkan bahwa sub sub variabel (first order) relevan dan berkontribusi menjadi komponen variabel (second order) formatif.

Setiap sub variabel dianggap tidak berkorelasi apabila nilai VIF di bawah 5 [23]. Pada uji collinearity (Tabel 4) tidak terdeteksi gejala collinearity karena nilai VIF setiap sub 
Tabel 4.

Uji Internal Consistency Reliability

\begin{tabular}{lcc}
\hline \hline Konstruk & Cronbach's Alpha & $\begin{array}{c}\text { Composite } \\
\text { Reability }\end{array}$ \\
\hline Utilitarian Value & 0,699 & 0,834 \\
Hedonic Value & 0,821 & 0,893 \\
Social Value & 0,857 & 0,913 \\
Privacy Risk & 0,921 & 0,944 \\
Performance Risk & 0,658 & 0,809 \\
Security Risk & 0,699 & 0,834 \\
Conflict Risk & 0,883 & 0,945 \\
Willlingness to Use & 0,837 & 0,891 \\
\hline
\end{tabular}

Tabel 5.

Weight Sub Variabel

\begin{tabular}{rlr}
\hline \hline Variabel & \multicolumn{1}{c}{ Sub Variabel } & Weight \\
\hline Perceived Value & Utilitarian Value & 0,372 \\
& Hedonic Value & 0,500 \\
& Social Value & 0,368 \\
Perceived Risk & Privacy Risk & 0,400 \\
& Performance Risk & 0,233 \\
& Security Risk & 0,345 \\
& Conflict Risk & 0,236 \\
\hline \hline
\end{tabular}

variabel kurang dari 5. Hasil tersebut menunjukkan tidak adanya korelasi antara sub variabel.

\section{B. Model Pengukuran (Outer Model)}

Pada model stuktural evaluasi dilakukan untuk melihat hubungan antar variabel laten. Untuk mengukur model structural dapat dilihat melalui nilai $R$ square, effect size, dan structural model path coefficients.

Nilai $\mathrm{R}^{2}$ variabel willingness to use adalah 0,452. Hal tersebut berarti bahwa persentase keragaman data dalam variabel willingness to use yang dapat dijelaskan oleh variabel perceived value dan perceived risk sebesar 45,2\%, sedangkan sisanya $54,8 \%$ dijelaskan oleh faktor lainnya di luar penelitian ini.

Nilai effect size merupakan ukuran untuk menilai kontribusi variabel eksogen terhadap variabel endogen [23]. Nilai $f$ square pada penelitian ini menunjukkan kebaikan model atau model yang memiliki pengaruh paling kuat adalah variabel perceived value dengan variabel willingness to use sebesar 0,323. Sementara model hubungan antara perceived risk dan willingness to use memiliki pengaruh moderate dengan nilai 0,178 .

Setelah melakukan uji kelayakan model, nilai goodness of fit dapat diketahui dengan menghitung menggunakan nilai AVE dan nilai R-Square dengan perhitungan sebagai berikut.

$$
\begin{aligned}
& G O F=\sqrt{\overline{A V E} \times \overline{R^{2}}} \\
& G O F=\sqrt{0,717 \times 0,452}=0.569
\end{aligned}
$$

Hasil di atas menunjukkan bahwa model penelitian ini dapat dikatakan robust, atau dikatakan memiliki model fit yang baik karena nilainya lebih dari 0,38[24].

\section{Uji Hipotesis}

Uji hipotesis akan dijelaskan berdasarkan hasil penelitian dan dihubungkan dengan teori yang membangun model penelitian.

Hasil PLS-SEM menunjukkan bahwa hubungan antara perceived value dan willingness to use memiliki nilai $p$-value 0,000 seperti yang tercantum pada Tabel 5. Nilai $p$-value kurang dari 0.05 sehingga dapat dinyatakan adanya pengaruh signifikan diantara dua variabel tersebut. Selain itu, nilai path
Tabel 2.

Uji Collinearity

\begin{tabular}{clc}
\hline \hline Variabel & \multicolumn{1}{c}{ Sub Variabel } & VIF \\
\hline Perceived Value & Utilitarian Value & 1,803 \\
& Hedonic Value & 2,252 \\
& Social Value & 1,341 \\
Perceived Risk & Privacy Risk & 1,715 \\
& Performance Risk & 1,640 \\
& Security Risk & 2,226 \\
& Conflict Risk & 1,676 \\
\hline \hline
\end{tabular}

Tabel 3.

\begin{tabular}{crrrl}
\multicolumn{5}{c}{ Path Coefficients } \\
\hline Hipotesis & $\begin{array}{c}\text { Path } \\
\text { Coefficient }\end{array}$ & \multicolumn{1}{c}{ statistic } & \multicolumn{1}{c}{ value } & Keterangan \\
\hline H1 & 0,460 & 4,452 & 0,000 & Diterima \\
H2a & 0,372 & 8,064 & 0,000 & Diterima \\
H2b & 0,500 & 11,460 & 0,000 & Diterima \\
H2c & 0,368 & 5,148 & 0,000 & Diterima \\
H3 & $-0,351$ & 2,809 & 0,005 & Diterima \\
H4a & 0,400 & 6,436 & 0,000 & Diterima \\
H4b & 0,233 & 4,319 & 0,000 & Diterima \\
H4c & 0,345 & 6,324 & 0,000 & Diterima \\
H4d & 0,236 & 5,024 & 0,000 & Diterima \\
H5 & 0,083 & 0,935 & 0,350 & Ditolak \\
\hline \hline
\end{tabular}

coefficients bernilai positif sebesar 0,460 yang menunjukkan bahwa perceived value memiliki pengaruh positif terhadap willingness to use. Hal tersebut berarti bahwa semakin besar perceived value maka willingness to use pengguna aplikasi carpooling semakin besar. Sehingga, dapat disimpulkan bahwa hipotesis 1 diterima dan sesuai dengan penelitian sebelumnya [7] [25]. Hal tersebut berarti untuk meningkatkan keinginan untuk menggunakan apikasi carpooling, perusahaan harus meningkatkan kualitas layanannya. Untuk meningkatkan penilaian manfaat aplikasi carpooling, perusahaan dapat memperhatikan harga, kemudahan, kenyamanan, dan bagaimana interaksi sosial antar pengguna.

Hasil menunjukkan bahwa hubungan antara utilitarian value, hedonic value, dan social value dengan perceived value memiliki nilai p-value kurang dari 0.05 mengindikasikan bahwa terdapat hubungan yang signifikan antara utilitarian value, hedonic value, dan social value dengan perceived value. Dengan kata lain berarti bahwa utilitarian value, hedonic value, dan social value merupakan komponen yang signifikan dari perceived value. Sehingga, dapat disimpulkan bahwa hipotesis 2a, 2b, dan 2c diterima dan sesuai dengan penelitian sebelumnya [7]. Hal tersebut berarti utilitarian value, hedonic value, dan social value merupakan dimensi yang relevan dan perceived value dapat diukur menggunakan dimensi tersebut. Hasil tersebut berarti bahwa pengguna carpooling mobile application memperhatikan nilai fungsional (utilitarian value), nilai emosional (hedonic value), dan nilai sosial (social value) sebagai pertimbangan dalam penilaian perceived value.

Berdasarkan hasil seperti yang tercantum pada Tabel 5 menunjukkan bahwa hubungan antara perceived risk dan willingness to use memiliki pengaruh yang signifikan dengan nilai $p$-value 0,005 . Nilai path coefficient antara dua variabel tersebut adalah -0,351 yang menunjukkan nilai negatif sehingga dapat dapat dikatakan bahwa perceived risk memiliki pengaruh negatif terhadap willingness to use. Hal tersebut berarti bahwa semakin besar nilai perceived risk maka willingness to use pengguna aplikasi carpooling semakin kecil. Hipotesis 3 diterima dan sesuai dengan penelitian sebelumnya [7][26][27]. 
Penggunaan layanan carpooling mobile application memiliki kemungkinan memberikan konsekuensi negatif kepada penggunanya. Untuk meningkatkan keinginan dalam menggunakan aplikasi, perusahaan harus meminimalkan risiko yang ada.

Hasil analisis PLS-SEM menunjukkan bahwa hubungan antara privacy risk, performance risk, security risk, dan conflict risk dengan perceived risk memiliki nilai p-value kurang dari 0.05 mengindikasikan bahwa terdapat hubungan yang signifikan antara privacy risk, performance risk, security risk, dan conflict risk dengan perceived risk. Hal tersebut berarti bahwa keempat dimensi merupakan komponen yang signifikan dari perceived risk. Sehingga, dapat disimpulkan bahwa hipotesis 4a, 4b, 4c, dan 4d diterima dan sesuai dengan penelitian sebelumnya [7]. Hal tersebut berarti privacy risk, performance risk, security risk, dan conflict risk merupakan dimensi yang relevan untuk perceived risk. Sehingga perceived risk dapat diukur menggunakan keempat dimensi tersebut. Dengan kata lain, pengguna carpooling mobile application mempertimbangkan masalah privasi, kinerja yang buruk, masalah keamanan, dan masalah manajemen penyelesaian konflik sebagai risiko yang dirasakan dalam penggunaan aplikasi

Hasil PLS-SEM pada Tabel 5 menunjukkan bahwa hubungan antara perceived value dan willingness to use memiliki nilai $p$-value 0.350 apabila dimoderasi oleh perceived risk. Nilai p-value lebih dari 0.05 mengindikasikan bahwa hubungan tersebut tidak signifikan. Hal tersebut berarti bahwa perceived value tidak memengaruhi willingness to use apabila terdapat moderasi dari perceived risk. Adanya variabel perceived risk sebagai moderasi memperlemah hubungan antara perceived value dengan willingness to use. Sehingga, dapat disimpulkan bahwa hipotesis 5 ditolak. Hasil penelitian ini tidak sesuai dengan penelitian sebelumnya yang telah dilakukan Wang et al. [7] bahwa perceived risk berpengaruh positif sebagai moderasi hubungan perceived value dengan willingness to use. Hal tersebut memunculkan indikasi bahwa terdapat faktor lain yang memengaruhi hubungan antara perceived value terhadap willingness to use carpooling mobile application di Indonesia.

\section{Implikasi Manajerial}

Berdasarkan hasil analisis PLS-SEM, perceived value yang besar dapat meningkatkan willingness to use carpooling mobile application. Hal tersebut menunjukkan perusahaan dapat meningkatkan kualitas layanannya agar pengguna merasakan manfaat yang lebih besar. Dari dimensi nilai utilitarian/fungsional perusahaan dapat membuat program voucher atau potongan harga. Hal tersebut untuk lebih mengurangi biaya yang harus dikeluarkan oleh pengguna. Selain itu untuk memberikan kemudahan pengguna dalam melakukan pembayaran, perusahaan dapat memberikan beberapa pilihan pembayaran, tidak hanya menggunakan uang tunai, tapi juga bisa melalui mobile payment, seperti OVO, Dana, atau LinkAja. Berdasarkan dimensi hedonic/emosional perusahaan dapat menambahkan fitur fasilitas dan preferensi yang ditawarkan oleh pengemudi. Sehingga penumpang dapat memilih pengemudi berdasarkan fasilitas yang ditawarkan dan preferensinya sesuai dengan dengan kenyamanan penumpang. Beberapa contoh preferensi yang dapat dipilih yaitu, tumpangan khusus wanita, dilarang merokok, boleh membawa anak kecil dan lain-lain. Sementara fitur fasilitas, pengemudi dapat menulis fasilitas apa yang mereka tawarkan dalam mobil seperti AC, musik, pemberian permen, pemberian minum dan lain-lain. Sementara dari dimensi sosial, perusahaan dapat menambahkan fitur chat untuk sesama penumpang juga. Hal tersebut merupakan saran dari responden. Sehingga komunikasi juga dapat dilakukan sesama penumpang dan sesama penumpang bisa melakukan janjian.

Sementara nilai perceived risk yang rendah dapat meningkatkan willingness to use aplikasi carpooling. Sehingga upaya yang perlu dilakukan perusahaan adalah memperkecil risiko pada penggunaan layanan aplikasi carpooling dengan memperhatikan dimensi pada perceived risk. Untuk menjaga keamanan privacy perusahaan perlu membatasi akses untuk melihat nomer telepon antar pengguna. Dari dimensi security risk, perusahaan dapat menambah fitur emergency call yang dapat digunakan saat dalam perjalanan apabila terjadi keadaan darurat. Kemudian perusahaan dapat meminimalkan conflict risk dengan cara memberikan penawaran asuransi perjalanan. Hal tersebut merupakan upaya proteksi apabila terjadi kecelakaan pada perjalanan agar para pengguna mendapatkan kompensasi.

\section{KESIMPULAN}

\section{A. Simpulan}

Berdasarkan analisis PLS-SEM, dapat disimpulkan bahwa terdapat pengaruh positif dan signifikan dari perceived value terhadap willingness to use carpooling mobile application. Hal tersebut berarti bahwa semakin tinggi nilai yang dirasakan oleh pengguna maka semakin tinggi keinginan pengguna untuk menggunakan aplikasi carpooling. Sementara perceived risk berpengaruh negatif dan signifikan terhadap willingness to use carpooling mobile application. Hal tersebut berarti bahwa semakin rendah risiko yang dirasakan oleh pengguna maka semakin tinggi keinginan pengguna untuk menggunakan aplikasi carpooling.

\section{B. Keterbatasan dan Saran}

Keterbatasan pada penelitian ini adalah jumlah sampel yang masih cenderung sedikit sehingga kurang mampu merepresentasikan hasil penelitian yang mencakup kondisi pengguna carpooling mobile application di Indonesia. Hal tersebut karena tidak diketahui seberapa efektif penyebaran data yang dilakukan dan bagaimana pendekatan yang paling efektif dalam menjangkau responden yang merupakan pengguna aplikasi carpooling. Selain itu pada penelitian ini juga hanya melihat dari perspektif penumpang. Padahal agar pengguna aplikasi carpooling bisa meningkat maka jumlah penumpang dan pemberi tumpangan harus seimbang. Terakhir nilai kekuatan prediktif model yang belum meiliki hubungan yang kuat, yang berarti bahwa faktor-faktor yang mempengaruhi willingness to use di Indonesia tidak hanya dipengaruhi oleh dua faktor yang digunakan pada penelitian ini.

Saran untuk penelitian selanjutnya yaitu adalah dapat menambahkan jumlah sampel yang digunakan pada penelitian terkait carpooling agar hasil analisis lebih akurat dengan menggunakan pendekatan yang tepat untuk menjangkau 
responden. Selain itu juga dapat melihat dari perspektif pemberi tumpangan, tidak hanya dari perspektif penumpang saja. Sehingga perusahaan dapat meningkatkan jumlah pengguna yang mau memberikan tumpangan. Penambahan alat analisis juga dapat dilakukan pada penelitian selanjutnya seperti analisis multi atribut. Sehingga dapat dianalisis atribut aplikasi carpooling apa yang perlu diprioritaskan. Untuk meninkatkan nilai prediktif model, penelitian selanjutnya dapat menggali faktor-faktor lain yang mempengaruhi willingness to use carpooling mobile application.

\section{DAFTAR PUSTAKA}

[1] BPS, "Perkembangan Jumlah Kendaraan Bermotor Menurut Jenis, 19492017," $2018 . \quad$ [Online]. https://www.bps.go.id/linkTableDinamis/view/id/1133. [Accessed: 27Sep-2019].

[2] T. A. Litman and W. E. Doherty, "Executive Summary of Transportation Cost and Benefit Analysis Techniques, Estimates and Implications," Transp. Cost Benefit Anal. Tech. Estim. Implic., 2009.

[3] BeritaSatu, "Sistem Ganjil-Genap Pengganti Aturan 3 in 1," 2016. [Online]. https://www.beritasatu.com/megapolitan/370863/sistem-ganjilgenappengganti-aturan-3-in-1. [Accessed: 28-Sep-2019].

[4] Detik, "Pro Kontra ASN Bandung Wajib ke Kantor Pakai Grab," 2019. [Online]. Available: https://news.detik.com/berita-jawa-barat/d4463294/pro-kontra-asn-bandung-wajib-ke-kantor-pakai-grab. [Accessed: 28-Sep-2019].

[5] Dinas Pariwisata Kutai Timur, "Konsep Dasar dan Penerapan A4 Dalam Dunia Pariwisata - Berit," 2017. [Online]. Available: https://dinaspariwisata.kutaitimurkab.go.id/news/6-konsep-dasar-danpenerapan-a4-dalam-dunia-pariwisata. [Accessed: 10-Oct-2019].

[6] BPS, "Statistik Wisatawan Nusantara 2018," 2018.

[7] Y. Wang, J. Gu, S. Wang, and J. Wang, "Understanding consumers' willingness to use ride-sharing services: The roles of perceived value and perceived risk," Transp. Res. Part C Emerg. Technol., vol. 105, no. May, pp. 504-519, 2019.

[8] F. Bachmann, A. Hanimann, J. Artho, and K. Jonas, "What drives people to carpool? Explaining carpooling intention from the perspectives of carpooling passengers and drivers," Transp. Res. Part F Traffic Psychol. Behav., vol. 59, pp. 260-268, 2018.

[9] A. Gheorghiu and P. Delhomme, "For which types of trips do French drivers carpool? Motivations underlying carpooling for different types of trips," Transp. Res. Part A Policy Pract., vol. 113, no. 11, pp. 460-475, 2018.

[10] A. Salamanis, D. D. Kehagias, D. Tsoukalas, and D. Tzovaras, "Reputation assessment mechanism for carpooling applications based on clustering user travel preferences," Int. J. Transp. Sci. Technol., vol. 8, no. 1, pp. 68-81, 2019.
[11] C. Wang, "Consumer acceptance of self-service technologies: An abilitywillingness model," Int. J. Mark. Res., vol. 59, no. 6, pp. 787-802, 2017.

[12] C. Hohenberger, M. Spörrle, and I. M. Welpe, "Not fearless, but selfenhanced: The effects of anxiety on the willingness to use autonomous cars depend on individual levels of self-enhancement," Technol. Forecast. Soc. Change, vol. 116, pp. 40-52, 2017.

[13] V. A. Zeithaml, L. L. Berry, and A. Parasuraman, "Communication and Control Processes in the Delivery of Service Quality," J. Mark., vol. 52, no. 2 , p. 35, 1988.

[14] C. L. Hsu and J. C. C. Lin, "What drives purchase intention for paid mobile apps?-An expectation confirmation model with perceived value," Electron. Commer. Res. Appl., vol. 14, no. 1, pp. 46-57, 2015.

[15] J. Hwang and M. A. Griffiths, "Share more, drive less: Millennials value perception and behavioral intent in using collaborative consumption services," J. Consum. Mark., vol. 34, no. 2, pp. 132-146, 2017.

[16] D. J. Kim, "Trust and satisfaction, two stepping stones for successful ecommerce relationships: A longitudinal exploration," Inf. Syst. Res., 2008.

[17] G. R. Dowling and R. Staelin, "A Model of Perceived Risk and Intended Risk-Handling Activity," J. Consum. Res., vol. 21, no. 1, p. 119, 1994.

[18] M. S. Featherman and P. A. Pavlou, "Predicting e-services adoption: A perceived risk facets perspective," Int. J. Hum. Comput. Stud., vol. 59, no. 4, pp. 451-474, 2003.

[19] M. W. Hawapi, Z. Sulaiman, U. H. Abdul Kohar, and N. A. Talib, "Effects of Perceived Risks, Reputation and Electronic Word of Mouth (E-WOM) on Collaborative Consumption of Uber Car Sharing Service," IOP Conf. Ser. Mater. Sci. Eng., vol. 215, no. 1, 2017.

[20] C. Lee, M. Rahafrooz, and O. K. D. Lee, "What are the concerns of using a ride-sharing service?: an investigation of uber," AMCIS 2017 - Am. Conf. Inf. Syst. A Tradit. Innov., vol. 2017-Augus, no. May 2017, 2017.

[21] S. J. Hong, "Assessing economic value of reducing perceived risk in the sharing economy: The case of ride-sharing services," AMCIS 2017 - Am. Conf. Inf. Syst. A Tradit. Innov., vol. 2017-Augus, no. 2006, pp. 1-10, 2017.

[22] N. K. Maholtra, Marketing Research: An Applied Orientation, Sixth Edit. Pearson Education Limited, 2010.

[23] J. F. Hair, G. T. M. Hult, C. M. Ringle, and M. Sarstedt, A primer on partial least squares structural equation modeling (PLS-SEM), Second Edi., vol. 38, no. 2. Los Angeles: Sage Publications, 2017.

[24] M. Tenenhaus, S. Amato, and V. E. Vinzi, "A Global Goodness-of-Fit Index for PLS Structural Equation Modelling," Proc. XLII SIS Sci. Meet., pp. 739-742, 2004.

[25] G. Zhu, K. K. F. So, and S. Hudson, "Inside the sharing economy. International Journal of Contemporary Hospitality Management," Int. J. Contemp. Hosp. Manag., vol. 29, no. 9, pp. 2218-2239, 2017.

[26] Z. W. Y. Lee, T. K. H. Chan, M. S. Balaji, and A. Y. L. Chong, "Why people participate in the sharing economy: an empirical investigation of Uber," Internet Res., vol. 28, no. 3, pp. 829-850, 2018.

[27] L. S. L. Chen, "The impact of perceived risk, intangibility and consumer characteristics on online game playing," Comput. Human Behav., vol. 26, no. 6, pp. 1607-1613, 2010. 